Employee of: AbbVie, Patrick Zueger Shareholder of: AbbVie, Employee of: AbbVie, Jacqueline O'Brien Employee of: Corrona, Heather J. Litman: None declared, Hua Feng Employee of: Corrona, Robert McLean: None declared

\begin{tabular}{|c|c|c|c|c|c|c|}
\hline \multicolumn{7}{|c|}{ aatient clinical and disease activity } \\
\hline \multirow[b]{2}{*}{ Variable } & \multicolumn{5}{|c|}{ Line of Therapy } & \multirow[b]{2}{*}{ P.value } \\
\hline & $\underset{(n=1516)}{\text { All }}$ & $\underset{(n=396)}{1^{31}}$ & $\underset{(n=453)}{2^{\text {nd }}}$ & 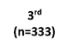 & $\begin{array}{l}\text { ath-or- } \\
\text { Higher } \\
\text { (n=334) }\end{array}$ & \\
\hline $\begin{array}{l}\text { Minimal Disease } \\
\text { Activity, } n(\%)\end{array}$ & $235(20.3)$ & $73(23.9)$ & $83(23.2)$ & $44(17,4)$ & $35(14.4)$ & 0.01 \\
\hline $\begin{array}{l}\text { Tender Joint Count 28, } \\
\text { meants }\end{array}$ & $4.5 \pm 5.8$ & $4.2 \pm 5.3$ & $4.3 \pm 6.0$ & $4.8 \pm 6.2$ & $4.7 \pm 5.7$ & 0.21 \\
\hline $\begin{array}{l}\text { Swollen Joint Count } 28, \\
\text { mean } 5 \mathrm{D} \text {, }\end{array}$ & $2.5 \pm 3.6$ & $3.0 \pm 4.0$ & $2.5 \pm 3.7$ & $2.3+3.5$ & $2.3+3.1$ & 0.01 \\
\hline $\begin{array}{l}\text { Enthesitis category }>0 \text {, } \\
n(\%)\end{array}$ & $380(30.1\}$ & $96(27.7)$ & $102(26.4)$ & $96(35.8)$ & $86(33.1)$ & 0.03 \\
\hline $\begin{array}{l}\text { Dactyilitis category }>0, \\
n(\%)\end{array}$ & 190 (15.1) & $70(20.2)$ & $49(12.7)$ & $34(12.7)$ & $37(14.2)$ & 0.02 \\
\hline HAQ $>1, n$ (\%) & $483(39.1\}$ & $108(32.3)$ & $146(38.2)$ & $104(39.7)$ & $125(48.8)$ & 0.001 \\
\hline $\begin{array}{l}\text { Body surface area } \leq 3 \% \% \\
\text { affected by psoriasis, n } \\
\text { (\%) }\end{array}$ & $790\{64.2\}$ & $215(64.8)$ & 239 (62.9) & $165(62.7)$ & $171(67.1)$ & 0.69 \\
\hline $\begin{array}{l}\text { Patient reported } \\
\text { fatigue 0-100, } \\
\text { meantSD }\end{array}$ & $50.7 \pm 28.2$ & $45.1 \pm 28.7$ & $49.7 \pm 29.4$ & 53.4425 .8 & $56.8 \pm 26.4$ & $<0.001$ \\
\hline $\begin{array}{l}\text { Patient overall pain } \\
0-100, \text { mean } \leqslant S D\end{array}$ & $51.5 \pm 28.2$ & $46.6 \pm 29.0$ & $49.2 \pm 28.6$ & $54.8+26.4$ & $58.2 \pm 27.0$ & $<0.001$ \\
\hline $\begin{array}{l}\text { Morring stiffness } \geq 30 \\
\min n(\%) \text { ( } 6 \text {. }\end{array}$ & $950(77.2)$ & $241(72.2)$ & $293(77.1)$ & $212(80.9)$ & $204(80.0)$ & 0.046 \\
\hline
\end{tabular}

DOI: 10.1136/annrheumdis-2019-eular.817

\section{FRI0439 PERCEIVED INFLUENCE OF HEALTH STATUS ON SEXUAL ACTIVITY IN PATIENTS WITH PSORIATIC ARTHRITIS IS ASSOCIATED WITH MUSCULOSKELETAL MANIFESTATIONS BUT NOT WITH PSORIASIS SKIN MANIFESTATIONS}

Glenn Haugeberg', Brigitte Michelsen', Arthur Kavanaugh'2. 'Sørlandet Hospital, Rheumatology, Kristiansand, Norway, ${ }^{2}$ UCSD Medical Center, Rheumatology, San Diego, United States of America

Background: Psoriatic arthritis (PsA) is a heterogeneous disease involving multiple domains including the musculoskeletal system and the skin. The disease may have a significant impact on various aspects of quality of life including sexuality.

Objectives: To explore the prevalence of self-reported problems with sexual activity in patients with PsA, and any associations with demographic and disease related variables as well as treatment.

Methods: PsA patients were consecutively recruited from a Norwegian rheumatology outpatient clinic. Data collection included information on demographics, measures of PsA disease activity (both skin and musculoskeletal manifestations), patient reported outcome measures and treatment. The perceived effect of health status on sexual activity was assessed using question 15 in the Health Related Quality of Life (HRQoL) instrument 15D. The question reads: My state of health: 1. Has no adverse effect on my sexual activity. 2. Has a slight effect on my sexual activity. 3. Has a considerable effect on my sexual activity. 4. Makes sexual activity almost impossible. 5. Makes sexual activity impossible. For analytical purposes the answers were dichotomized into "no/little negative effect" (answers 1 and 2) and "large negative effect" (answers 3-5). For group comparisons we used Chi-square test for categorical variables and student t-test for continuous variables. Adjusted logistic regression models were also applied.

Results: Among the 135 PsA patients assessed mean (SD) age was 52.1 (10.2) years and $51.1 \%$ were men. The majority of patients (111 patients, $82.2 \%$ ) reported their state of health to have no/little effect on their sexual activity and 24 patients (17.8\%) reported their state of health to have large negative effect on their sexual activity.

Patients with a large negative effect of their health status on sexual activity had significantly longer disease duration as well as higher DAPSA, MASES and fatigue score compared with the patients reporting no/little impact of their health status on sexual activity (table).

In adjusted logistic regression models with disease duration, DAPSA, MASES and fatigue in the model, only disease duration and MASES were independently associated with a large negative effect on sexual activity, this also when adjusting for age and sex.

Conclusion: Approximately $20 \%$ of the PsA patients reported their health status to have a large negative effect on their sexual activity. Only disease duration and measures reflecting musculoskeletal disease were found to have a negative effect on sexual activity among PsA patients; skin psoriasis did not have an impact.
Disclosure of Interests: Glenn Haugeberg Grant/research support from: For this study grant from Biogen, Consultant for: Medical Advisory boards for several companies, Paid instructor for: I have been paid for giving lectures for pharmaceutical companies and their employees, Speakers bureau: I have been paid for giving lectures in meetings organized by pharmaceutical companies, Brigitte Michelsen: None declared, Arthur Kavanaugh Grant/research support from: UCB Pharma DOI: 10.1136/annrheumdis-2019-eular.3444

\begin{tabular}{|c|c|c|c|c|}
\hline & $\begin{array}{c}\text { Total } \\
(n=135)\end{array}$ & $\begin{array}{c}\text { No/little effect } \\
(n=111)\end{array}$ & $\begin{array}{l}\text { Large negative effect } \\
\qquad(n=24)\end{array}$ & $\begin{array}{c}\mathrm{P}- \\
\text { values }\end{array}$ \\
\hline Age $(\mathrm{SD})$ years & $\begin{array}{c}52.1 \\
(10.2)\end{array}$ & $51.8(10.3)$ & $53.3(10.3)$ & 0.54 \\
\hline Men, n (\%) & $\begin{array}{c}69 \\
(51.1 \%)\end{array}$ & $58(52.3 \%)$ & $11(45.8 \%)$ & 0.57 \\
\hline BMI (SD) kg/m2 & $\begin{array}{l}28.2 \\
(4.4)\end{array}$ & $28.1(4.2)$ & $29.1(5.0)$ & 0.34 \\
\hline Smoking & $\begin{array}{c}21 \\
(15.6 \%)\end{array}$ & $16(14.4 \%)$ & $5(20.8 \%)$ & 0.43 \\
\hline $\begin{array}{l}\text { Disease duration (SD) } \\
\text { years }\end{array}$ & $8.7(6.7)$ & $8.1(6.6)$ & $11.6(6.5)$ & 0.02 \\
\hline 68 Tender Joint Count & $\begin{array}{l}10.1 \\
(11.1)\end{array}$ & $9.1(10.2)$ & $14.7(13.8)$ & 0.07 \\
\hline 66 Swollen Joint Count & $0.6(1.1)$ & $0.6(1.1)$ & $0.6(0.9)$ & 0.96 \\
\hline DAPSA & $\begin{array}{c}18.2 \\
(14.2)\end{array}$ & $16.8(13.3)$ & $24.8(16.6)$ & 0.01 \\
\hline MASES & $2.9(3.1)$ & $2.5(2.9)$ & $4.4(3.5)$ & 0.01 \\
\hline Fatigue (VAS 0-100) & $\begin{array}{l}45.1 \\
(32.4)\end{array}$ & $42.2(32.4)$ & $58.1(29.6)$ & 0.03 \\
\hline Pain (VAS 0-100) & $\begin{array}{l}33.7 \\
(23.1)\end{array}$ & $32.1(22.8)$ & $41.3(23.5)$ & 0.08 \\
\hline MHAQ & $\begin{array}{c}0.42 \\
(0.40)\end{array}$ & $0.39(0.34)$ & $0.58(0.58)$ & 0.12 \\
\hline PASI skin score & $2.5(3.6)$ & $2.4(3.6)$ & $3.1(4.0)$ & 0.38 \\
\hline Current Biologics & $\begin{array}{c}44 \\
(32.6 \%)\end{array}$ & 36 (32.4\%) & $8(34.8 \%)$ & 0.83 \\
\hline Current DMARDs & $\begin{array}{c}79 \\
(58.5 \%)\end{array}$ & $68(61.3 \%)$ & $11(45.8 \%)$ & 0.16 \\
\hline
\end{tabular}

\section{FRI0440 THE EFFECT OF GUSELKUMAB ON PASDAS, GRACE INDEX, MCPDAI, AND DAPSA: RESULTS FROM A PHASE 2 STUDY IN PATIENTS WITH ACTIVE PSORIATIC ARTHRITIS}

Dafna D. Gladman ${ }^{1}$, Philip Helliwell ${ }^{2}$, Atul Deodhar ${ }^{3}$, Alice B. Gottlieb ${ }^{4}$, WolfHenning Boehncke ${ }^{5}$, Xie L. Xu' ${ }^{6}$, Stephen $\mathrm{Xu}^{6}$, Yuhua Wang ${ }^{6}$, Elizabeth C. Hsia ${ }^{6,7}$, Christopher T. Ritchlin $8 .{ }^{1}$ Centre for Prognosis Studies in The Rheumatic Diseases, Toronto, Canada; ${ }^{2}$ University of Leeds, Leeds, United Kingdom; ${ }^{3}$ Oregon Health and Science U, Portland, United States of America; ${ }^{4}$ cahn School of Medicine at Mt Sinai, Dermatology, New York, United States of America; ${ }^{5}$ Geneva University Hospitals and Department of Pathology and Immunology, University of Geneva, Geneva, Switzerland; ${ }^{6}$ Janssen Research and Development, LLC, Spring House, United States of America; ${ }^{7}$ Univ of Penn Medical Center, Phila, United States of America; ${ }^{8}$ University of Rochester, Rochester, United States of America

Background: Psoriatic ArthritiS Disease Activity Score (PASDAS), GRAppa Composite scorE (GRACE) Index, modified Composite Psoriatic Disease Activity Index (mCPDAl), and Disease Activity Index for PSoriatic Arthritis (DAPSA) are composite indices recently developed to assess disease activity in psoriatic arthritis (PsA). ${ }^{1,2}$

Objectives: The effect of guselkumab (GUS) on these indices was evaluated in a phase 2 study in patients with active PsA.

Methods: Patients with $\geq 3$ tender and $\geq 3$ swollen joints, C-reactive protein $\geq 3 \mathrm{mg} / \mathrm{L}$, and $\geq 3 \%$ body surface area (BSA) of plaque psoriasis despite treatment were randomized 2:1 to receive GUS $100 \mathrm{mg}$ subcutaneously $(\mathrm{N}=100)$ or placebo (PBO, $\mathrm{N}=49$ ) at Weeks 0,4 , and every 8 weeks thereafter through Week44. At Week16, patients with $<5 \%$ improvement in both swollen and tender joint counts were eligible for early escape $(E E)$ to open-label ustekinumab. All remaining PBO patients crossed-over to receive GUS $100 \mathrm{mg}$ at Weeks 24, 28, 36, and 44 (PBO $\rightarrow$ GUS). The PsA composite indices through Week24 were analyzed using last-observation-carried-forward for missing data and data post EE. After Week24, observed data were used. Missing baseline data were excluded in the analyses.

Results: Baseline PASDAS, GRACE, mCPDAI, and DAPSA showed moderate to high disease activity (mean (SD): 6.53 (1.079), 6.08 (1.208), 7.6 (2.15), and 46.65 (20.391), respectively), and were generally comparable between PBO and GUS. At Week24, GUS significantly decreased PASDAS, GRACE, mCPDAI, and DAPSA scores (mean (SD) change from baseline: -2.50 (1.59), -2.73 (1.76), -3.8 (2.72), 
-23.08 (20.21), respectively) vs PBO (mean (SD) change from baseline: 0.49 (1.33), $\quad-0.35$ (1.39), $\quad-0.8$ (2.16), $\quad-4.97$ (20.11), respectively, all $\mathrm{p}<0.001)$. Significantly more GUS-treated patients achieved a low or very low disease activity state defined by PASDAS, GRACE, and mCPDAI $(35.0 \%, 29.6 \%$, and $45.9 \%$, respectively) vs $\mathrm{PBO}(4.1 \%, 2.1 \%$, and $10.4 \%$, respectively, all $\mathrm{p}<0.001)$. In addition, $12 \%$ of GUS- vs $0 \%$ of PBO-treated patients achieved DAPSA remission $(p<0.01)$. Post Week24, improvements in PASDAS, GRACE, mCPDAI, and DAPSA were also observed in PBO $\rightarrow$ GUS patients $(39.3 \%, 39.3 \%, 71.4 \%$ and $50.0 \%$ achieved disease activity states of low, very low, or remission at Week 44, respectively), and were maintained through Week44 in GUS patients (45.8\%, 42.2\%, 62.7\%, and $51.1 \%$ achieved disease activity states of low, very low, or remission, respectively).

Conclusion: GUS demonstrated consistent improvements based on all PsA composite indices evaluated, and efficacy was maintained through Week44.

\section{REFERENCES:}

[1] Helliwell PS, FitzGerald O, and Fransen J. JRheumatol 2014;41:12121217.

[2] Scholes MM, Aletaha D, Alasti F, Smolen JS. AnnRheumDis 2016;75:811818.

Disclosure of Interests: Dafna D Gladman Grant/research support from: AbbVie, Amgen, Celgene, Lilly, Novartis, Pfizer, and UCB, Consultant for: AbbVie, Amgen, BMS, Celgene, Galapagos, Gilead, Janssen, Lilly, Novartis, Pfizer, and UCB, Philip Helliwell Grant/research support from: Paid to charity: from AbbVie, Janssen and Novartis, Consultant for: Paid to charity: from AbbVie, Amgen, Pfizer, and UCB and Celgene. Paid to self: from Celgene and Galapagos, Atul Deodhar Grant/research support from: AbbVie, Amgen, Eli Lilly, GSK, Janssen, Novartis, Pfizer, and UCB, Consultant for: AbbVie, Amgen, BMS, Eli Lilly, Janssen, Novartis, Pfizer, and UCB, Alice B Gottlieb Grant/research support from: PI: Incyte Corporation, Janssen-Ortho Inc., Lilly ICOS LLC, Novartis, UCB, XBiotech, Consultant for: AbbVie, Dermira, Incyte Corporation, Lilly ICOS LLC, Novartis, Sun Pharmaceutical Industries Ltd., Avotres (unpaid), XBiotech (unpaid), Speakers bureau: AbbVie, Eli Lilly and Company, Janssen Biotech; advisory board: Bristol-Myers Squibb, Celgene Corporation, Janssen Biotech, Janssen-Ortho Inc., LEO Pharma, Novartis, UCB, Wolf-Henning Boehncke Consultant for: Pfizer Inc, Speakers bureau: Pfizer Inc, Xie L Xu Employee of: Employee of Janssen Research \& Development, LLC, Stephen Xu Employee of: Employee of Janssen Research \& Development, LLC, Yuhua Wang Employee of: Employee of Janssen Research \& Development, LLC, Elizabeth C Hsia Employee of: Employee of Janssen Research \& Development, LLC, Christopher T. Ritchlin Grant/research support from: AbbVie, Amgen, UCB Pharma, Consultant for: AbbVie, Amgen, Lilly, Novartis, Pfizer, UCB Pharma

DOI: 10.1136/annrheumdis-2019-eular.177

\section{FRI0441 LONG DISEASE DURATION PREDICTED NON- ALCOHOLIC FATTY LIVER DISEASE IN PSORIATIC ARTHRITIS}

Grace Chup-Hei Ho. Queen Elizabeth Hospital, Medicine, Kowloon, Hong Kong (SAR)

Background: Psoriasis is known to be associated with non-alcoholic fatty liver disease (NAFLD). Previously studies showed that patients with psoriatic arthritis (PsA) were of higher risk of developing NAFLD compared to non-PsA individuals.

Objectives: To study the prevalence of NAFLD among patients with PsA and factors predicting the development of NAFLD.

Methods: This retrospective study was carried out in a tertiary hospital. Adult patients (>18-year-old) with PsA who attended rheumatology specialist outpatient clinic between 1st Jan 2016 and 31st Dec 2018 were included. Demographic and clinical (disease duration, comorbidities, investigation results and treatment profile) data of these patients were obtained. NAFLD was diagnosed by either imaging or histology. Logistic regression was used to identify factors predicting NAFLD.

Results: 223 patients (male 53\%, female 47\%) with a mean age of 58year-old and mean disease duration of 10.5 years were included in the study. Patients with NAFLD $(n=58,26 \%)$, compared to those without, tended to be older (mean age 59.0-year-old vs 57.6-year-old) and had higher proportion of male (64\% vs $51 \%)$.

Among the patients with NAFLD, $30(51.7 \%)$ had transient abnormal liver function test but none resulted in hepatic failure or death. 10 patients $(17.2 \%)$ had their treatment for PsA withheld or changed as a result of abnormal liver function due to NAFLD.
Long disease duration (OR 1.005, $\mathrm{p}<0.01$ ), but not age, predicted NAFLD. In particular, those with disease duration of 10 years or more were of higher risk (OR 2.79, $\mathrm{p}<0.001$ ). Cardiovascular risk factors including hypertension, diabetes mellitus, dyslipidaemia, and established cardiovascular diseases were not found to be predictors of NAFLD among PsA. None of the treatment agents including steroid, conventional synthetic or biological disease modifying anti-rheumatic durgs (DMARDs) was found to be risk factor for NAFLD.

Conclusion: NAFLD was common among patients with PsA, though it seldom led to significant hepatic impairment or interruption of treatment of PsA. Patients with longer duration of psoriatic arthritis were at risk of developing fatty liver. Traditional cardiovascular risk factors, established cardiovascular diseases or use of any particular treatment agent were not found to be predicting factor of development of NAFLD in PSA.

\section{REFERENCES :}

[1] Aliment Pharmacol Ther. 2015 Feb;41(3):293-300

[2] J Invest Dermatol. 2018 Apr;138(4):760-767

Disclosure of Interests: None declared

DOI: 10.1136/annrheumdis-2019-eular.7564

\section{FRI0442 EFFECTIVENESS OF YTTRIUM KNEE SYNOVECTOMY IN PSORIATIC OR SERONEGATIVE ARTHRITIS WHO HAVE FAILED CONVENTIONAL THERAPY}

Mark Hoey, Victoria Mcdowell, Adrian Pendleton. Musgrave Park Hospital, Rheumatology, Belfast, United Kingdom

Background: Radiation synovectomy with Yttrium $90 \mathrm{Y}$ is indicated for refractory arthritis of various aetiologies e.g. inflammatory joint diseases such as rheumatoid arthritis, seronegative arthritidies such as psoriatic arthritis and reactive arthritis, Haemophilic arthritis, Calcium pyrophosphate dihydrate (CPPD) arthritis and pigmented villonodular synovitis (PVNS) ${ }^{1}$.

Treatment of inflammatory arthritis has improved due to more effective therapy and earlier treatment therefore Yttrium therapy is less commonly used.

Objectives: To assess the response to Yttrium 90Y synovectomy in patients with Psoriatic arthritis or seronegative arthritis with synovitis affecting the knee joint in a cohort of patients who had failed conventional DMARDs, biological DMARDs or intra-articular steroid injections. To identify any possible predictors of good or poor response. To develop a standard operating procedure to improve consistency and also allow service to be potentially expanded.

Methods: Retrospective chart and electronic care record review of al patients receiving Yttrium therapy in Northern Ireland from March 2016 to April 2018. Patient demographics, MRI findings, conventional and biological DMARD use, previous intra-articular steroid use were recorded Patients were reviewed approximately six months following treatment. The medical notes were reviewed to decide whether there had been a good or poor response to treatment and data analyzed to look for factors that may predict response. The process was evaluated and we developed a standard operating procedure to improve consistency and safety going forward.

Results: 17 patients in total received Yttrium therapy, 9 males. Age range was 18-75 with a mean 41.10 patients were diagnosed with seronegative arthritis and 7 with psoriatic arthritis. All patients had an MRI of the affected joint(s) which confirmed synovitis in all cases. 9 MRIs showed no significant degenerative changes, 5 showed mild degenerative changes and 3 moderate/severe. All patients had previously received intra-articular steroid injection. 12 patients also were receiving or had failed treatment with a conventional or biological DMARD.

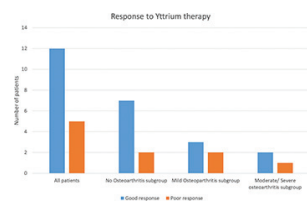

Each knee received a dose of $180 \mathrm{MBq}$ Yttrium under direct ultrasound guidance in addition to Triamcinolone $40 \mathrm{mg}$ and using Lidocaine $1 \%$ loca anaesthesia. 3 patients received treatment for both knees.

Reviewing all patients $71 \%$ (12/17) reported good efficacy. $78 \%$ (7/9) of patients reported good efficacy in group with no osteoarthritis on MRI, $60 \%(3 / 5)$ in the mild osteoarthritis group and $67 \%(2 / 3)$ in the moderate to severe osteoarthritis group. BMI, Age, sex or underlying diagnosis did 